\title{
Unsteady Second Grade Fluid with Oscillatory Boundary Conditions Between two Parallel Plates.
}

\author{
Liaqat $\mathrm{Ali}^{1}$, Taza $\mathrm{Gul}^{2}$, and Saeed Islam \\ ${ }^{1}$ Iqra National University \\ ${ }^{2}$ City University of Science and Information Technology \\ ${ }^{3}$ Affiliation not available
}

July 9, 2020

\begin{abstract}
In the present work flow is developed for unsteady MHD 2nd grade fluid between two periodically oscillating plates. The flow behavior is categorized in the three cases, namely Couette flow, Poiseuillie flow and combination of these two flows. The partial differential equation arises from modeling of these problems have been analytically solved by using two well-known techniques Optimal Homotopy Asymptotic Method (OHAM) and Adomian Decomposition Method (ADM). The comparison of these two methods has been shown numerically as well as graphically and found in excellent agreement. Finally the heat transfer analysis and the effect of physical parameters during periodic motion of fluid flow has been analyzed and discussed
\end{abstract}

\section{Hosted file}

Final ManuscritP18.docx available at https://authorea.com/users/341137/articles/468096unsteady-second-grade-fluid-with-oscillatory-boundary-conditions-between-two-parallelplates 